Running Head: SCHOOL DISCIPLINE AND SELF-CONTROL

The association between school discipline and self-control from preschoolers to middle school students: A three-level meta-Analysis

\title{
Jian-Bin $\mathrm{Li}^{*}$
}

Department of Early Childhood Education, The Education University of Hong Kong, Hong Kong

Centre for Child and Family Science, The Education University of Hong Kong, Hong Kong E-mail: lijianbin@eduhk.hk

Shan-Shan Bi

Department of Interdisciplinary Social Sciences, Utrecht University, Utrecht E-mail: $\underline{\text { s.bi@uu.nl }}$

Yayouk E Willems

Department of Biological Psychology, Vrije Universiteit Amsterdam, Amsterdam

Amsterdam Public Health Institute, Amsterdam, the Netherlands

Department of Interdisciplinary Social Sciences, Utrecht University, Utrecht

E-mail: y.e.willems@,vu.nl

Catrin Finkenauer

Department of Interdisciplinary Social Sciences, Utrecht University, Utrecht

E-mail: c.finkenauer@uu.nl

Corresponding author:

Jian-Bin Li, Ph.D.

Assistant Professor

Department of Early Childhood Education

The Education University of Hong Kong

10, Lo Ping Road,

Tai Po, New Territories, Hong Kong

E-mail: lijianbin@eduhk.hk

Tel: +85229487587

Fax: +85229487160 


\begin{abstract}
Self-control plays a significant role in child and adolescent development. The school environment is suggested as an important factor associated with individual differences in self-control. Among the many facets of school environment, school discipline is thought of as a critical factor that distinguishes students with good self-control from those with poor self-control. However, the existing findings are mixed. To take stock of the literature, this meta-analysis summarizes the overall association between three components of school discipline (i.e., structure, support, and teacher-student relationship) and self-control in students from preschool to high school. Based on 65 studies reporting 247 effect sizes $(N=$ $55,940)$, the results show that school discipline is positively related to self-control $(r=.189$, $p<.001,95 \% \mathrm{CI}=[.148, .229])$. No significant publication bias was found. Moderator analyses showed that effect sizes are similar in magnitude across students' sex, age, and ethnicity, school level, discipline level, culture (individualism and power distance), informant of school discipline and self-control, research design, and time lag. The effect size was stronger for the teacher-student relationship component and for studies using the same informant to assess the two constructs. These findings point to the importance of school discipline, particularly a good teacher-student relationship, associated with individual differences in self-control in students from preschool to middle school.
\end{abstract}

Key words: self-regulation; authoritative discipline; structure; support; teacher-student relationships; meta-analysis. 


\section{The association between school discipline and self-control from preschoolers to middle school students: A three-level meta-Analysis}

Developmental outcomes in childhood and adolescence have long-lasting impact on the physical and psychological well-being in adulthood (McLeod \& Almazan, 2003; Patton et al., 2016, 2018; Pulkkinen, Nygren, \& Kokko, 2002). Successfully navigating day-to-day challenges requires, among other capabilities and competences, self-control (Caspi et al., 2016; Moffitt et al., 2011; Moffitt, Poulton, \& Caspi, 2013). Self-control refers to the ability to alter one's cognition, emotion, impulsive tendencies, and behaviors to align with social norms, personal standards, and to support the pursuit of goals (Baumeister, Vohs, \& Tice, 2007; Tangney, Baumeister, \& Boone, 2004). Numerous studies have demonstrated that children and adolescents with high levels of self-control, compared to their counterparts with low levels of self-control, have better academic performance, physical health, well-being, social competence, and less school dropout and fewer emotional and behavioral problems (e.g., Duckworth \& Seligman, 2005; Eisenberg et al., 2001; Galla \&

Duckworth, 2015; Moffitt et al., 2011; Li, Delvecchio, Lis, Nie, \& Di Riso, 2015; Li \& Lau, 2018; Nie, Li, \& Vazsonyi, 2016).

The importance of self-control for a wide array of life domains has triggered a large number of studies investigating its etiological sources. Although self-control has its biological underpinnings, it is also substantially shaped by the environment (Willems et al., 2018, 2019). Most of the existing studies consider the family as the primary developmental context for child and adolescent self-control. Indeed, prior meta-analyses have summarized that positive parenting, good parent-child relationship, secure attachment to parents, and 
non-violent family environment are significantly related to better self-control in children and adolescents (Davis, Bilms, \& Suveg, 2017; Karreman, van Tuijl, van Aken, \& Deković, 2006; Li et al., 2019; Pallini et al., 2018; Willems, Li, Hendriks, Bartels, \& Finkenauer, 2018).

Besides family, the school and interaction with school authorities (e.g., teachers) become another important part of the developmental context for children when they start formal education (Bronfenbrenner, 1979; Downer, Sabol, \& Hamre, 2010). In fact, scholars have commonly agreed that school environment is an indispensable context for the development of self-control (Gottfredson \& Hirschi, 1990; Sameroff, 2010). Among the many facets of school environment, school discipline, pertaining to the discipline practices in the school settings such as structure, support, and teacher-student relationship (Gregory et al., 2010), is suggested to be especially crucial in distinguishing students with low and high levels of self-control. Recently, an increasing number of studies have investigated the relation between school discipline and child and adolescent self-control (e.g., Batanova \& Loukas, 2016; Brody, Dorsey, Forehand, \& Armistead, 2002; Cadima et al., 2019; Intravia, Jones, \& Piquero, 2012), but the existing findings are inconsistent in terms of magnitude and directionality. Policy-makers and school authorities often rely on scientific research to determine which practices should be used to keep students in line (Luke, 2009), but inconsistent results across the literature prevent policy makers from identifying the most effective approach. Thus, it is important to take stock of the existing findings and inform the field about whether school discipline is related to self-control in children and adolescents; and if yes, how strong these associations are, and for whom and under which 
conditions the associations are strongest.

A recent meta-analysis examined the overall association between teacher-student relationship and executive functions in children up to 12 years (Vandenbroucke, Spilt, Verschueren, Piccinin, \& Baeyens, 2018). Based on 23 studies, it found that a high-quality teacher-student relationship is related to children's better general executive functioning, working memory, and inhibition, but not to cognitive flexibility. The current meta-analysis adds additional important knowledge in several aspects. First, school discipline is a broad construct that comprises of different components. The previous meta-analysis only focused on the teacher-student relationship, neglecting other crucial components that define school discipline (e.g., structure and support). The current study considers teacher-student relationship and other components simultaneously to identify their unique associations with self-control. Second, the previous meta-analysis focused on children, but did not consider middle school students. Most middle school students are in the adolescent period, a stage characterized by substantial changes in social relationships and increased sensitivity to external stimuli (e.g., peer pressure) that cause self-control failure (Smetana, Campione-Barr, \& Metzger, 2006; Steinberg, 2004; Steinberg \& Morris, 2001). Given that self-control is a robust factor that aids adolescents to overcome challenges and facilitates positive youth development (Moffit et al., 2011; Caspi et al., 2016), understanding whether school discipline is associated with adolescent self-control is critical. The current study focuses on multiple developmental periods ranging from preschool to middle school, which provides a more complete picture of the association between school discipline and self-control in its developmental context. Third, the prior meta-analysis focused on 
executive function (EF). Although EF (a construct often studied in psychology) is related to self-control, self-control (a construct that is used in research spanning the behavioral and social science) is typically considered a broader concept (Nigg, 2017). This study focuses on self-control, thus providing a complementary view for the issue. Finally, the previous meta-analysis did not employ advanced meta-analytical techniques, such as three-level meta-analysis, to deal with dependency issue or decompose variance at the sample, within-study, and between-study levels. Not taking these issues into account may yield an underestimation of the standard error and favor statistical significance (Hox, Moerbeek \& Van de Schoot, 2010; Viechtbauer, 2013). Given these gaps, this study aims to conduct a three-level meta-analysis to summarize the overall association between school discipline and self-control from preschoolers to middle school students.

\section{Conceptualization of self-control}

Self-control is widely studied in different social and behavioral disciplines and the conceptualization of self-control differs by theoretical tradition, with developmental psychologists often referring to effortful control (e.g., Eisenberg et al., 2003, 2005), while personality and social psychologists often interchangeably refer to self-control and self-regulation (Gottfredson \& Hirschi, 1990; Tangney et al., 2004). Despite the differences in the labels or definitions of self-control in the literature, extant theories and empirical findings agree that self-control and its analogous terms (e.g., self-regulation, self-discipline, effortful control, executive control, delay of gratification) tap into a common capacity. The common thread underlying these terms is the involvement of voluntary self-management, an ability one uses to govern his/her cognition, emotion, impulse, performance, and 
behavior (Bridett, Burt, Edwards, \& Deater-Deckard, 2015; Duckworth \& Kern, 2011; Nigg, 2017). This is supported by different lines of research. For instance, factor analyses of tasks developed based on different conceptualizations of self-control found that these tasks were best reflected by a one-factor model (Allan, Hume, Allan, Farrington, \& Lonigan, 2014; Allan \& Lonigan, 2011). Moreover, a study meta-analyzing correlation between self-control measures derived from different theories revealed moderate convergence (Duckworth \& Kern, 2011). In addition, studies from neuroscience also yielded that the neural substrates related to different conceptualizations of self-control overlapped (Fan, Flombaum, McCandliss, Thomas, \& Posner, 2003; Garavan, Ross, Murphy, Roche, \& Stein, 2002). Hence, in this study we refer to self-control and relevant terms as "self-control" in general, as many other meta-analyses about self-control do (Davis et al., 2017; De Ridder, Lensvelt-Mulders, Finkenauer, Stok, \& Baumeister, 2012; Li et al., 2019; Pallini et al., 2018; Vazsonyi et al., 2017; Willems et al., 2018; Willems, Boesen, Li, Finkenauer, \& Bartels, 2019).

\section{School discipline and self-control}

The school has clear interest in maintaining discipline to control students' misbehavior, ensure an environment conducive to learning and teaching, and facilitate academic performance (Gottfredson \& Hirschi, 1990; Gregory et al., 2010; Lee \& Croninger, 1996). This suggests school discipline should be beneficial to the development of students' self-control. There have been wide variations in the approaches school authorities adopt to manage their students' behavior, ranging from strict and demanding behavioral conformity to autonomy-granting and independent decision-making (Kupchik, 
2010; Stronach \& Piper, 2008). In the literature of parenting, structure (reflected as strictness, limit setting, monitoring and supervision, etc.) and support (reflected as parent support, involvement, etc.) are identified as two central components of effective parenting (Baumrind, 1996; Darling \& Steinberg, 1993). Inspired by this typology, scholars applied structure and support to school-wide conditions as two approaches to discipline students, and considered that these two components are not mutually exclusive but rather interdependent in disciplining children (e.g., Gregory \& Cornell, 2009; Gregory et al., 2010; Jia, Konold, \& Cornell, 2016; Konold et al., 2014). Besides structure and support, it is crucial to include teacher-student relationship (reflected as closeness, dependency, attachment, etc.) as part of school discipline. Support and teacher-student relationships are similar to some extent yet distinct in several aspects. Support guides students' behavior and facilitates learning at the classroom level, and concerns the management of student behavior; by contrast, the teacher-student relationship focuses on the quality and security in the teacher-student relationship at the interpersonal level, and concerns the affective quality of the relationship (Roorda, Koomen, Spilt, \& Oort, 2011; Vandenbroucke et al., 2018). In addition, support is assumed to be instrumental in guiding students' behavior, while the teacher-student relationship is more purely affective (Roorda et al., 2011). Distinguishing these two constructs may provide richer information about the relative strength of the role of support and teacher-student relationship quality, respectively. Hence, in this study, we summarize the associations between three school discipline components (i.e., structure, support, and teacher-student relationship) and self-control.

The association between structure and self-control. Structure refers to the extent 
to which school authorities socialize students and enforce rules in a consistent manner, and thereby corresponds to the discipline component in the parenting literature (Gregory \& Cornell, 2009; Gregory et al., 2010). Good structure can be indicated as school authorities' implementation of setting clear limits, close monitoring of and consistent discipline of students' misbehavior, and establishing well-organized environments that facilitate students' learning and internalization of rules. By contrast, poor structure can be represented as ambiguous rules, loose monitoring of students' (mis)behavior, inconsistent discipline of students' misbehavior, and chaotic environments that hamper students' learning and internalization of rules.

Existing literature has discussed how structure impacts self-control. According to Gottfredson and Hirschi's (1990) general theory of crime, self-control develops through authorities' (e.g., teachers) monitoring of children's behavior, which aids in recognizing their misbehavior and timely correcting such misbehavior. These discipline encounters provide children with abundant information regarding rules, boundaries, and others' expectations. It is during this process that children learn what they are permitted and not permitted to do and develop self-control to initiate what they should do and inhibit what they should not do (Bergin \& Bergin, 1999). In addition, the deterrence theory considers that the violation of socially appropriate behavior can be curbed by making noncompliance costly for individuals (Gibbs, 1975). Applied to school settings, by exerting self-control students intentionally control their behavior and obey rules to abide by school norms and standards, because they want to avoid the negative consequences associated with their misbehavior. Gregory et al. (2010) posited that when exposed to structure that involves fair 
and consistent supervision and monitoring, students experience legitimate and non-arbitrary use of authority. Although students may antagonize school discipline at the beginning, they tend to comply when they discover that discipline is fair and consistent, which helps them internalize rules that guide their self-controlled behavior in the long-run (Bergin \& Bergin, 1999).

Previous studies have examined the relationship between structure and self-control, but the findings are mixed. For instance, in a study conducted among Korean secondary students, teachers' monitoring and recognition of students' misbehavior were not related to self-control, but teachers' discipline was (Moon, McCluskey, Blurton, \& Hwang, 2014). In a study carried out among kindergarten teachers and preschoolers, teachers' managing children's misbehavior in the classroom was related to more self-control in children (Bennett, Elliott, Peters, 2005). However, another study found that teachers' socialization of preschoolers' misbehavior was related to less self-control in children (Degol \& Bachman, 2015).

The association between support and self-control. Support can be defined as the extent to which students feel their school authorities are caring and concerned about them (Gregory, Cornell, \& Fan, 2011). This component reflects teacher-student interactions occurring in the school/classroom context (Vandenbroucke et al., 2018). High support can be reflected as school authorities and teachers' involvement in and caring about child wellbeing, child-oriented behavior (e.g., listen to their needs), granting autonomy, and providing emotional and instructional support (e.g., providing explanations, resources). By contrast, low support can be indicated as school authorities and teachers' low involvement 
and indifference toward child wellbeing, teacher-oriented behavior, provision of little or no autonomy, emotional, or instructional support. High support provides supportive control that scaffolds students to explore autonomous self-control and manage their behavior (Roorda et al., 2011).

The self-determination theory proposes that relatedness, competence, and autonomy are the three basic needs which comprise of the fundamental motivations that drive human behavior such as self-control (Deci \& Ryan, 2000, 2008; Reeve, Ryan, Deci, \& Jang, 2008). In line with this theory, when students perceive that the school and teachers care about them, grant them with autonomy, and allow them to make decision on their own, students are more willing to voluntarily initially internalize and comply with school authorities' rules and norms firmly and enduringly, which promotes their self-control in the long-run (Niemiec et al., 2006). Moreover, when students perceive that they are in a supportive environment and feel being supported and respected, they are more open and more willing to comply with authorities' rules and discipline (Gregory et al., 2010).

Although a number of studies have examined the relationship between support and self-control, the results are not consistent. For instance, a study conducted among Turkish and U.S. adolescents found that high levels of school support were significantly related to emotional and behavioral self-control with medium effect size (Telef \& Furlong, 2017). A longitudinal study among Dutch adolescents found that the association between autonomy support and delay of gratification was significant across different waves but the coefficients reduced over time (Schuitema, Peetsma, \& van der Veen, 2016). Besides, some studies conducted among preschoolers revealed that teachers' emotional and instructional support 
was not significantly related to behavioral self-control among U.S. and Dutch kindergarten children (Broekhuizen, Slot, van Aken, \& Dubas, 2017; Rimm-Kaufman, Curby, Grimm, Nathanson, \& Brock, 2009).

\section{The association between teacher-student relationship on self-control.}

Teacher-student relationships can be defined as the quality of affectional bonding between teacher (and other school authorities) and a specific student at the dyadic level (Vandenbroucke et al., 2018). High quality relationships can be described as relationships with high levels of closeness, close bonding and harmony, secure attachment, high levels of warmth and sensitivity to students' needs. By contrast, low quality relationships can be represented as relationships with low levels of closeness, heightened alienation, increased conflict, insecure attachment, and low sensitivity to students' needs.

According to Bowlby's (1969) attachment theory, a secure attachment with parents is the foundation for children to regulate their emotions and behavior, which serves as the prototype for subsequent self-control (Bowlby, 1969; Cassidy, 1994; Kopp, 1982).

Specifically, when children feel secure and safe with significant attachment figures (usually parents), they are more willing to work out self-control challenges without being afraid of rejection by attachment figures even though they may fail. Besides parents, teachers become attachment figures after children enter school. Applying the attachment framework to understand the influence of teacher-student relationship on students' outcomes, scholars postulate that a secure attachment and a close relationship with teachers are preconditions for students' exploration and internalization of rules (Sabol \& Pianta, 2012; Verschueren \& Koomen, 2012; Verschueren et al., 2018). In addition, the general theory of crime implies 
that an effective control of children's misbehavior is a crucial means to instill them with self-control, and that a good (teacher-student) relationship is the foundation for effective discipline (Gottfredson \& Hirschi, 1990). This theory also claims that students who like and attach to school are willing to comply with school rules and are afraid of being punished.

A number of studies have examined the association between teacher-student relationship and self-control, but, again, results are disparate. For instance, a study conducted among African American and Hispanic boys found that teacher-reports of teacher-student relationships was significantly related to higher attentional and emotional control, but children's reports of teacher-student relationships were not (Barbarin et al., 2013). Moreover, some studies found that attachment to school was positively related to self-control at medium to large effect sizes (e.g., Xia, Fosco, \& Feinberg, 2016), while others found that the two constructs are correlated only with small effect sizes (e.g., Cheung \& Cheung, 2008).

\section{Moderators}

As shown above, the findings of the associations between different components of school discipline and self-control are inconsistent, suggesting that these associations may be moderated by one or more other factors such as age, sex, and culture. In this study, we took into account a wide range of potential theoretical and methodological moderators that were frequently included in prior meta-analyses.

Components of school discipline. As discussed above, the three components may affect self-control through different mechanisms. Structure operates by directly socializing 
children's behavior so as to instill rules and norms. Support operates by providing students with a caring and respecting environment that facilitates students' autonomous self-control. Teacher-student relationship operates by establishing a secure psychological base for children to explore self-control. Scholars have considered that teacher-student relationship is a foundation for support and structure (Vandenbroucke et al., 2018). Other scholars have posited that without providing structure, support and teacher-student relationship are not enough to teach students self-control (Gregory et al., 2010). In order to distinguish the relative strength of the three components in relation to self-control, we explore the moderating effect of school discipline components.

Student sex. Research on gendered socialization finds that the etiological processes of self-control vary among boys and girls (Hagan, Simpson, \& Gillis, 1987; Hayslett-McCall \& Bernard, 2002). According to the gendered socialization perspective, girls may benefit more from close relationships with teachers because closeness is consistent with the gender role of girls and teachers show more intimacy towards girls (Maccoby, 1998). Moreover, misbehavior is less accepted for girls than for boys and it is argued that teachers have stricter attitudes towards girls' misbehavior than towards boys' misbehavior (Ewing \& Taylor, 2009). However, according to the risk perspective, boys are more at-risk than girls in misbehavior and thus require more assistance and discipline (Bristol, 2015; Monroe, 2006). In this study, we explore whether students' sex moderates the association between school discipline and self-control.

Student age. While evidence suggests that self-control continues to develop until mid-20s (Cohen et al., 2016), scholars have theorized that self-control mainly develops in 
childhood (Gottfredson \& Hirschi, 1990). This claim is supported by recent empirical findings which suggest that self-control develops faster during childhood, but its development decelerates in adolescence (Vazsonyi \& Jiskrova, 2018). Literature has suggested that younger children are more likely to be influenced by environmental factors than are older children, and that middle school students become less connected to teachers and parents than younger students (Buhrmester \& Furman, 1987; Hargreaves, 2000; Lynch \& Cicchetti, 1997). However, empirical studies reveal different findings. For instance, school support was significantly related to self-control in adolescents but not in children (Broekhuizen, et al., 2017; Rimm-Kaufman et al., 2009; Schuitema et al., 2016; Telef \& Furlong, 2017). Thus, in this study we explore whether age moderates the association between school discipline and self-control.

School level. Besides age, we are also interested in exploring the moderating role of another age-related factor: school level. Students show different discipline problems at different school levels (e.g., elementary vs. middle school, Theriot \& Dupper, 2010). We consider that discipline may be more important in middle school, because in this period students are in their adolescent period, a period filled with drastic changes that could often lead to self-control failure (Li et al., 2019). Thus, to ensure the order for learning and teaching, middle school may stress discipline more and this may have stronger association on students' self-control compared to lower school levels. To understand whether the associations between school discipline and self-control differ at different school levels, we also explore whether they vary across preschoolers, primary school students, and middle school students. 
Culture and ethnicity. It is found that countries' economies and cultural values are related to students' perception of classroom discipline, with students from countries that are poor, equal and have rigid gender roles reporting higher classroom discipline (Chiu \& Chow, 2011). In this sense, there is a possibility that the associations between school discipline and self-control vary across cultures/countries. To model this, in this study we examine several potential culture-related moderators. We investigate whether power distance (the extent to which people accept inequalities) and individualism (the extent to which people are interdependent and prioritize group goals and values over personal ones), two important components of Hofstede's (2001) cultural model, play a moderating role. In some societies, people are more accepting of social hierarchy where power is distributed unevenly (power distance) and emphasize interdependency and in-group goals (collectivism) more than people from other societies; these cultural features strongly influence individuals' personality, their interactions with people, and the way they discipline their children and students (Hofstede \& McCrae, 2004; Oyserman, Coon, \& Kemmelmeier, 2002; Schwab, 2013). Moreover, some studies involve samples from different ethnicities. Besides cultural values, investigating whether ethnicities moderates the "school discipline - self-control" association may provide a more complete picture. For these reasons, we explore whether cultural dimensions (i.e., power distance and individualism) and participants' ethnicity moderate the targeted associations.

Discipline level. Literature on school discipline considers that discipline can be implemented at both classroom and school levels (Gregory et al., 2010; Gregory \& Weinstein, 2004, 2008). Discipline at the classroom level mainly refers to the authoritative 
teaching, teachers' relationships with students, and supportive climate that happen in classroom contexts, while discipline at the school level mainly refers to the school-wide discipline. Correspondingly, scholars measure constructs such as teacher support, classroom organization, attachment to teacher, teacher-student relationship to reflect classroom-wide discipline (e.g., Graziano, Garb, Ros, Hart, \& Garcia, 2016; Ponitz, Rimm-Kaufman, Brock, \& Nathanson, 2009), but measure constructs such as attachment to school, school organization, schools' discipline, school supervision to indicate school-level discipline (e.g., Alvarez-Rivera, Price, \& Ticknor, 2017; Batanova \& Loukas, 2016; Blanc, Vallières, \& McDuff, 1992). However, differences in the magnitude of association between classroom-wide discipline and self-control and the one between school-wide discipline and self-control are not well quantified. Therefore, we explore whether discipline level moderates the targeted associations.

Report informant. Research often uses diverse approaches to assess school discipline as well as self-control. Some studies employ self-report measures, some utilize other-report measures (e.g., parent- or teacher-report), some use behavioral and observational methods, and some even adopt more than one approach. Since teachers, observers, and parents may have different attitudes and experiences towards school discipline and students' self-control ability (Duckworth \& Kern, 2011; Lanz, Scabini, Vermulst, \& Gerris, 2001), results may vary across informants. In this study, we explore whether report informant of school discipline and self-control measures moderates the "school discipline - self-control" associations.

Consistency of report informant. Based on report-informant of school discipline 
and self-control measures, we further explore whether the consistency of report informants of the two constructs plays a moderating role. Prior research has shown that the correlation of two variables is usually higher if they are measured with the same rather than different report informants (Meyer et al., 2001; Willems et al., 2018). Thus, we explore whether the association between school discipline and self-control is more pronounced when both constructs are assessed with the same (consistent) than with different (inconsistent) informants.

Study design. Prior studies employ both cross-sectional and longitudinal designs to investigate the association between school discipline and self-control. In a cross-sectional design, data regarding school discipline and self-control are collected at the same time point. As a result, the common method variance is likely to inflate the correlation between the two constructs, thus causing the cross-sectional correlations to be higher than longitudinal correlations (Lindell \& Whitney, 2001). In this study, we are also interested in exploring whether study design (cross-sectional vs. longitudinal) moderates the association between school discipline and self-control. To further triangulate the results, we further examine whether the time-lag between the assessments of the two constructs plays a moderating effect. In this case, cross-sectional studies have a time-lag of zero years, but the interval of time-lag varies for longitudinal studies.

\section{Method}

We set up this meta-analysis following the PRISMA flowchart (Moher et al., 2015). In order to facilitate transparency, we pre-registered this study at [website omitted for masked review purpose] (pre-registration number: 15602). 


\section{Search of studies}

We searched articles that were published up to the end of October 2018 through three electronic databases: the Education Resources Information Center (ERIC), PsycINFO, and PubMed with three categories of key phrases: (1) key words regarding school terms (i.e., teach* or class $*$ or school* or teacher-child* or teacher-student* or academic $*$ or educat* or disciplin* or preschool* or kindergarten), (2) key words regarding self-control terms (self-control or self-regulation or self-discipline or effortful control or executive* or impul* or delay of gratification), and (3) key words regarding students/children/adolescents (adolescen* or youth* or teen* or child* or student* or pupil*). In addition to electronic data bases, we also traced the reference list of the prior meta-analysis of similar topic (Vandenbroucke et al., 2018) and added potentially eligible studies for further coding.

\section{Inclusion criteria}

We used the following criteria to determine whether the studies were eligible for this meta-analysis. First, the study had to examine the association between any component of school discipline and self-control or interrelated concepts such as self-regulation, effortful control, delay of gratification or domain-specific forms of control (e.g., attentional, emotional, or behavioral control). If no correlations were reported in the article, we contacted the corresponding author. Our main focus was about the ability to alter dominant cognition, emotion, and behavior (e.g., inhibition, regulation, or initiation). Thus, for studies that examined executive functions, we only included correlations involving components such as inhibitory/executive control, but excluded other executive function components such as phonological loops, visual sketchpad, shifting, and working memory, 
as done by prior meta-analyses about self-control (Davis et al., 2017; De Ridder et al., 2012; Karreman et al., 2006; Li et al., 2019; Pallini et al., 2018; Vazsonyi et al., 2017; Willems et al., 2018, 2019).

Second, the study had to focus on community-based samples. We excluded clinical samples with physical (e.g., diabetes) and/or psychological (e.g., ADHD) symptoms, and/or criminal offenders, because these populations may affect the magnitude and/or direction of effect sizes (Rothbaum \& Weisz, 1994).

Third, the study had to focus on preschoolers to middle school students. We did not include university students, because universities rely more on students' autonomy and responsibility for their accomplishments, rather than the structure of the learning environment and teachers' activities. Moreover, preschoolers and most middle school students are still under legal age and are supposed to be more closely guided by family and school authority than university students.

Fourth, the study had to be published in English in a peer-reviewed journal and the full-text had to be downloadable. We did not include grey literatures (e.g., unpublished work, book chapters, dissertation, and conference papers), because findings in these are often published in journals later on, and this is a widely accepted practice in previous meta-analyses (e.g., Karreman et al., 2006; Li et al., 2019; Slagt et al., 2016). In fact, research finds that publication bias found in meta-analyses that include unpublished studies is just likely as in the ones that do not (Ferguson \& Brannick, 2012).

\section{Selection procedure}

The selection procedure is illustrated in Figure 1. The initial search resulted in 
13,756 hits after duplicates were removed. The first author, who was familiar with the field, screened all abstracts and selected 226 articles for text reading. A number of these articles were excluded because they did not meet one or more of the inclusion criteria. Specifically, 114 studies did not examine the topic we were interested in (i.e., the association between school discipline on self-control) or did not use appropriate measures to assess school discipline and/or self-control ; 5 studies focused on populations we were not interested in (e.g., university students, clinical samples); 14 studies were not published in peer-reviewed journals; 18 studies were not downloadable full-texts; and 23 studies did not provide the correlation coefficients in the text. For the latter 23 studies, we contacted the corresponding authors by e-mail. We received 4 replies (17.4\% responding rate) that provided us with the correlation we needed, and the remaining e-mails did not receive a response. In addition, we retrieved 9 eligible articles from the reference list in a prior meta-analysis which summarizes the relationship between teacher-student relationship and children's executive function (Vandenbroucke et al., 2018). Finally, a total of 65 studies were included in this meta-analysis.

\section{[INSERT FIGURE 1 ABOUT HERE]}

\section{Coding of the studies}

Following the guidelines proposed by Lipsey and Wilson (2001), we developed a coding scheme to record study descriptors and study characteristics. Study descriptors contain the basic information of the study, such as author names, year of publication, sample size, and so on. Study characteristics contain factors that possibly moderate the "school discipline - self-control" association. However, due to a number of reasons (e.g., 
not reported in the study, metrics not in comparable units, insufficient number of effect size), not all of our presumed moderators were included in statistics, such as teachers' teaching experience, teacher-student ratio, whether students are at-risk, school types, family socioeconomic status, etc. The second and third author coded $20 \%$ of the studies.

Due to the high inter-rater reliability, the remaining of the studies were coded by the second author and double checked by the first and the third author. In-depth reading and discussion within the research group were conducted to solve any disagreement.

Components of school discipline. To explore the moderating effect of the component of school discipline, we subdivided it into three categories: (1) structure (e.g., monitoring, supervision), (2) support (e.g., emotional support, autonomy support), and (3) teacher-student relationships (e.g., closeness, attachment). These components were coded categorically $(1=$ structure, $2=$ support , and $3=$ teacher-student relationships $)$. See Table 1 for a detailed overview of the subdivision of school discipline components.

\section{[INSERT TABLE 1 ABOUT HERE]}

Sex of students. We coded sex of students according to the proportion of boys included in the study continuously. Specifically, we used the ratio of boys as reference, such that a percentage higher than 50\% indicates the study included more boys than girls.

Age of students. We coded students' age continuously. Special attention was given to studies that reported grade instead of age. If this was the case, we took the average age of that grade. For instance, sixth graders in the USA are on average between 11-12 years old, and thus we considered 11.5 years an approximate mean age for this sample.

School level. We coded school level categorically. School level was coded into 
three categories: $1=$ within kindergarten (both constructs are assessed in kindergarten), $2=$ within primary school (both constructs are assessed in primary school), and $3=$ within middle school (both constructs are assessed in middle school).

Culture and ethnicity. In this study, we explored the moderating effects of two widely studied cultural dimensions, power distance and individualism. We coded the levels of power distance and individualism of the country where the data were collected based on Hofstede's scores (see www.hofstede-insights.com). These scores are continuous indexes, with a higher score indicating that individuals from a particular country are more accepting of inequalities (e.g., an index of 80 for China) and are more individualistic (e.g., an index of 90 for Australia). Moreover, regarding ethnicity, we coded this categorically: $1=$ balanced (i.e., no dominant ethnicity exceeded $60 \%$ of the sample), $2=$ most Caucasian (i.e., $>60 \%$ of the sample was Caucasian), $3=$ most African or African American (i.e., $>60 \%$ of the sample was African or African American), 4 = most Asian or Asian American (i.e., > $60 \%$ of the sample was Asian or Asian American), and $5=$ most Hispanic (i.e., $>60 \%$ of the sample was Hispanic), as has been done in prior research (Li et al., 2019).

Discipline level. Since discipline can be implemented at both school and classroom levels, we coded discipline level categorically: $1=$ school-wide, and 2 =classroom-wide. We coded this referring to the levels for the effect sizes stated in the study. Many studies explicitly stated the discipline level (e.g., school socialization, school supervision/control, classroom organization). Nevertheless, in some studies, the effect sizes were referred to as "teacher" (e.g., teacher support, attachment to teacher, teacher-student closeness/conflict). In this case, we coded these effect sizes as "classroom wide" because such discipline by 
teachers is likely to occur in the classroom context.

Report informant. For both school discipline and self-control, we coded informant categorically, 1 = student self-report, 2 = other-report (e.g., parent- and teacher-report), $3=$ observation or behavioral tasks, and $4=$ composite (i.e., combining measures of multiple informants or assessment modalities). After scrutinizing the other-report category of school discipline, we found that nearly all effect sizes measured by other-report were teacher-report except one (Turner, Piquero, \& Pratt, 2005). Thus, we dropped this specific cell so that all other-report school discipline indicated teachers' perspective of school discipline.

Consistency of report informant. We further categorically coded whether school discipline and self-control were assessed by the same informant or not: $1=$ consistent, $2=$ inconsistent. Special attention was given to the components that made up the composite score. For instance, if the composite score of school discipline comprised of self-report and teacher-report but the one of self-control comprised of self-report and a behavioral task, we coded this case, albeit both being composite, as inconsistent.

Research design. Finally, we categorically coded research design to reflect whether the associations were cross-sectional or longitudinal, $1=$ cross-sectional, and $2=$ longitudinal. In addition, we coded the time lag between the assessment of school discipline and self-control as a continuous variable (in years). For instance, if school discipline was assessed when students were 10 years old and self-control was assessed when students were age 12, then the time lag is coded as 2 years. For all cross-sectional studies, the time lag is coded as 0 years. 


\section{Inter-rater reliability}

Among the 65 studies, $20 \%$ of the articles were randomly selected for the second and the third author to double code. Intraclass correlation (ICC, for continuous variables) and Cohen's Kappa (K, for categorical variables) were calculated. The results showed excellent inter-rater reliability, ranging from .914 (research design) to 1.00 (individualism, power distance, and boys-girls ratio).

\section{Effect sizes}

Pearson's correlation coefficients $(r \mathrm{~s})$ were used as effect sizes in this meta-analysis. In order to keep the effect sizes in the same direction, we recoded the correlation coefficients if: (1) school discipline pertained to negative components (e.g., unorganized, unsupervised, friction) and (2) self-control pertained to negative expressions (e.g., low self-control, impulsivity). Fishers' $r-t o-z$ transformation was conducted to convert the raw correlation coefficients into an $E S z$ score. This $E S z$ corrects for skewness in the sampling distribution of the raw correlations and is assumed to approach normality, a necessary premise to ensure accurate estimation of the mean effect size and unbiased tests of statistical significance (Lipsey \& Wilson, 2001). After that, we used Fisher's z-to-r transformation to convert the mean effect size ESz back to Pearson's $r$ for interpretation purpose (Field, 2001; Lipsey \& Wilson, 2001). Regarding categorical moderators, we transformed categories to $k$ - 1 dummy variables through binary coding (Assink $\&$ Wibbelink, 2016; Lipsey \& Wilson, 2001).

\section{Publication bias}

Prior research has shown that insignificant findings are more likely to be 
unsubmitted or rejected for publication (Torgerson, 2006; Lipsey \& Wilson, 2001). This well-known "file-drawer problem" may result in publication bias that inflates the estimated effect sizes in meta-analyses (Rosenthal, 1979). Therefore, it is crucial to gauge the possible influence of publication bias before interpreting the results. In this study, we dealt with this issue by utilizing a funnel plot in couple with Egger's test. Specifically, the distribution of effect sizes of each individual study on the horizontal axis against their standard errors on the vertical axis was plotted (Torgerson, 2006). An asymmetrical funnel plot would appear if publication bias affects the data (Begg, 1994). Moreover, we used Egger's test to test the significance of the asymmetry of the plot so as to provide more precise information on the presence or absence of publication bias (Egger, Smith, Schneider, \& Minder, 1997). If a significant result is found, we would continue using trim-and-fill method to correct the asymmetric plots by imputing the missing effect sizes (Duval \& Tweedie, 2000a, 2000b). However, it should be noted that imputing non-existing effect sizes is controversial and does not necessarily reflect the true effect, and thus one should interpret the results generated by trim-and-fill approach with caution (Sutton, Duval, Tweedie, Abrams, \& Jones, 2000).

\section{Dependency problem}

Many studies report more than one effect size. For instance, some studies include correlation between several IVs (e.g., teacher-student closeness, teacher-student conflict, teacher-student dependency) and a single DV (e.g., self-control), or vice versa. Moreover, some longitudinal studies report the correlation between an IV and a DV at multiple time points and/or from different report-informants. Effect sizes from the same study are likely 
to be more similar than the ones from different studies, because the former usually relies on the same sampling and data collection approach. In this case, the assumption of traditional meta-analysis that observations should be independent and error terms are uncorrelated is thus violated (Lipsy \& Wilson, 2001; Rosenthal, 1984). Dependency problems can result in biased standard errors and yields incorrect interferences (Hox et al., 2010; Viechtbauer, 2013).

There are three traditional approaches to handle the dependency problem: (1) select one representative effect size, (2) average all effect sizes within the same study, and (3) simply ignore this issue (Lipsey \& Wilson, 2001). However, each of these methods has obvious limitations that bias the results. Recently, three-level meta-analysis has been suggested as a more advanced tool to deal with such dependency issue, because it considers all the effect sizes and thus maximizes the information and yields greater statistical power (Assink \& Wibbelink, 2016; Hox et al., 2010; Van den Noortgate, López-Lopez, Marín-Martínez, \& Sánchez-Meca, 2013). This three-level meta-analysis allows us to calculate the variance at the sample level (level 1), at the "within-study" level (level 2, effect sizes nested in the same study), and at the "between-study" level (level 3, taking into account the variations of effect sizes between studies). As such, no greater weight will be placed on studies with more effect sizes than those with few effect sizes. Given that the three-level model is able to include all effect sizes, generate higher statistical power, and provide more precise estimation compared to traditional approaches, this study will use this method to deal with the dependency issue.

\section{Data analyses}


Data analyses were performed in R Studio (R Core Team, 2017) with the Metafor package (Viechtbauer, 2010). After conducting descriptive analyses to summarize the basic information of the effect sizes (e.g., number of effect sizes by types of school discipline, research design, publication year, etc.), we performed a three-level analysis in steps following the guideline by Wibbelink and Assink (2016). First, we calculated the overall mean effect sizes to assess the magnitude of the association between school discipline and self-control. Second, we conducted a likelihood test to estimate the within-study and between-study heterogeneity. Third, if the heterogeneity (presented as a $Q_{E}$ ) is significant and substantial (in this case, it means less than $75 \%$ of the variance is attributed to the sampling variance), it indicates examination of moderators of the overall effect can be fruitful (Hunter \& Schmidt, 1990). In this case, we continued testing the proposed moderators. To ensure the reliability of the results, moderation analyses were carried out only if each category of the moderator contained at least five effect sizes. In the moderation analyses, we first tested each moderator individually. Then, we examined all the significant moderators in a single "multiple moderation model" to control for multicollinearity. Finally, we assessed publication bias with funnel plot in coupled with Egger's test. Trim-and-fill method would be applied if significant bias was present. Finally, we used G*Power (Faul, Erdfelder, Lang, \& Buchner, 2007) to recommend sample sizes needed to achieve the average correlations between school discipline and self-control found in this study.

\section{Results}

\section{Descriptive statistics}

The current study included a total of 65 studies reporting 247 effect sizes with a 
total sample size ${ }^{1}$ of 55,940 participants and a mean age of 8.85 years old (ranging from 3 to 16.5 years old). The included studies were published between 1990 and $2019^{2}$. Most studies included both boys and girls, with some effect sizes referring to only boys (in this case, boys ratio was $100 \%$ ) while some to only girls (in this case, boys ratio was $0 \%$ ). Studies were conducted worldwide, spanning six continents (i.e., Africa, Asia, Australia, Europe, North America, and South America), but most of them were from U.S. (62.35\%) and the Netherlands (12.55\%). Detailed descriptive statistics are displayed in Table 1.

Moreover, Table 2 lists the specific terms in each included study that were coded into one of three school discipline components. It shows that classroom organization comprises of most cases in the structure component, while teachers' support, emotional support, and autonomy support comprised of most cases for the support component. Regarding the teacher-student relationship component, teacher-student closeness, teacher-student conflict, and students' attachment to school were the terms that prevailed in this component.

\section{[INSERT TABLE $1 \& 2$ ABOUT HERE]}

\section{Overall effect}

The overall effect size was significant, $E S_{z}=0.191, S E=0.021, t=9.000, p<.001$, $95 \% \mathrm{CI}=[0.149,0.233]$, with substantial heterogeneity, $Q_{E}(246)=4505.429, p<.001$. Using an inverse version of the Fisher's $r$-to- $z$ formula to transformed back the overall effect size and its 95\% confidence interval (CI) back to Person's correlation $r$ for

\footnotetext{
${ }^{1}$ If a study has multiple effect sizes with different sample sizes, we used the largest one for calculation.

${ }^{2}$ In our pre-registration, we had stated that we searched the literature up to the end of October 2018. However, when we downloaded some online-first articles, they had been arranged in an issue to be published in 2019 .
} 
interpretational purpose, we found that the overall association between school discipline and self-control was $r=.189,95 \% \mathrm{CI}=[.148, .229]$.

\section{Variance of overall effect}

The variances at the within-study level (estimate $=.011, p<.001)$ and at the between-study level (estimate $=.023, p<.001)$ were significant. Follow-up analyses found that the variance at the sampling, within-study, and between-study levels was $4.98 \%$, $30.93 \%$, and $64.09 \%$, respectively. According to Hunter and Schmidt (1990), if less than 75\% of the variance is composed by the sampling variance, then exploring the moderation effects of other factors (e.g., demographic, theoretical, and methodological moderators) on the overall effect size can be meaningful. In this study, only $4.98 \%$ variance was attributed to the samples, and thus we continued examining the potential moderators proposed above.

\section{Moderator analyses}

We tested moderators individually (see Table 3). As shown, among the thirteen moderators tested, we found that component of school discipline $\left(Q_{E}(244)=3305.091, p\right.$ $<.001, F(2,244)=5.524, p=.005)$, age of students $\left(Q_{E}(245)=4124.764, p<.001, F(1\right.$, $245)=8.117, p=.005)$, school level $\left(Q_{E}(226)=3743.528, p<.001, F(2,226)=4.123, p\right.$ $=.017)$, report informant of self-control measure $\left(Q_{E}(243)=3815.920, p<.001, F(3,243)\right.$ $=7.015, p<.001)$, consistency of report informant $\left(Q_{E}(242)=4005.349, p<.001, F(1,242)\right.$ $=23.512, p<.001)$, research design $\left(Q_{E}(245)=4394.913, p<.001, F(1,245)=4.098, p\right.$ $=.044)$, and time-lag $\left(Q_{E}(245)=4485.387, p<.001, F(1,245)=5.083, p=.025\right)$ were significant moderators. No other proposed moderators were statistically significant at the conventional level $(p<.05)$, including sex of students, individualism, power distance, 
ethnicity of students, discipline level, and report informant of school discipline measure.

\section{[INSERT TABLE 3 ABOUT HERE]}

\section{Significant moderators}

We continued with follow-up analyses based on the significant moderators found above and the results are summarized in Table 4. Regarding the component of school discipline, we found that all components were significantly associated with self-control. Results of further comparison showed no significant difference in magnitude between the "structure - self-control" association and the one of the "support - self-control" association $(E S z=0.043,95 \% \mathrm{CI}=[-0.020,0.105])$. However, the magnitude of the "teacher-student relationship - self-control" link was significantly larger than the one of the "structure self-control" link $(E S z=0.114,95 \% \mathrm{CI}=[0.045,0.182])$ and the "support - self-control" $\operatorname{link}(E S z=0.071,95 \% \mathrm{CI}=[0.009,0.133])$.

Regarding school level ${ }^{3}$, we found that the effect sizes for all the periods were significantly. Further comparison showed that the effect size for the association between school discipline and self-control "within kindergarten" was not significantly different from the one "within primary school" $(E S z=-0.022,95 \% \mathrm{CI}=[-0.118,0.075])$, but it was significantly smaller than the one "within middle school" $(E S z=0.121,95 \% \mathrm{CI}=[0.026$, 0.216]). Besides, the effect size for the "school discipline - self-control" link within

\footnotetext{
3 We also tested whether transition levels (i.e., school discipline was assessed at prior school level and self-control was assessed at later school level) and mixed level (i.e., school discipline and self-control were assessed in samples from more than one school level, such as students from primary and middle schools) had moderation effect by coding $1=$ within kindergarten, $2=$ within primary school, $3=$ within middle school, $4=$ within transition levels, and $5=$ mixed levels. The results showed that effect sizes from within kindergarten (slope $=0.156$, S.E. $=0.031, t=5.080, p<.001,95 \% \mathrm{CI}=$ $[0.096,0.217]$ ), within primary school (slope $=0.137$, S.E. $=0.041, t=3.348, p<.001,95 \% \mathrm{CI}=[0.056,0.217]$, and within middle school (slope $=0.280$, S.E. $=0.036, t=7.871, p<.001,95 \% \mathrm{CI}=[0.210,0.351]$ ) were significant, but the effect size for transition (slope $=0.102$, S.E. $=0.056, t=1.818, p=.070,95 \% \mathrm{CI}=[-0.008,0.212]$ ) and mixed levels (slope $=0.156$, S.E. $=0.110, t=1.422, p=.156,95 \% \mathrm{CI}=[-0.060,0.373]$ were not significant.
} 
primary school too was significantly smaller than the one within middle school $(E S z=$ $0.143,95 \% \mathrm{CI}=[0.033,0.252])$.

Regarding age of students, the regression coefficient was significant and positive. This suggests that the magnitude of the "school discipline and self-control" association is larger for older students.

Regarding the informant of self-control measure, we found that the association between school discipline and self-control was significant when self-control was assessed with self-report and other-report measures as well as observation/task, but insignificant when self-control was measured with composite measures (e.g., self-report measure + task). Results of further comparison showed that the magnitude of the "school discipline self-control" association was stronger for studies using self-report measures to assess self-control compared to the ones using other-report measures $(E S z=-0.089,95 \% \mathrm{CI}=$ $[-0.164,-0.015])$, observation/task $(E S z=-0.176,95 \% \mathrm{CI}=[-0.255,-0.097])$, and composite measure $(E S z=-0.189,95 \% \mathrm{CI}=[-0.301,-0.077])$. Moreover, the magnitude of the association was also stronger for effect sizes using other-report measure to assess self-control compared to the ones using observation/task $(E S z=-0.087,95 \% \mathrm{CI}=[-0.154$, $-0.019])$.

Regarding the consistency of report informant, we found that effect sizes were both significant for studies using consistent and inconsistent informant. Results of further comparison revealed that the effect sizes obtained from consistent report informant were significantly stronger than the ones obtained from inconsistent report informant $(E S z=$ $-0.141,95 \% \mathrm{CI}=[-0.199,-0.084])$. 
Regarding research design, we found that effect sizes were both significant for studies using cross-sectional and longitudinal design. Results of further comparison revealed that the effect sizes obtained from cross-sectional design were significantly stronger than the ones obtained from longitudinal studies $(E S z=-0.048,95 \% \mathrm{CI}=[-0.094$, $-0.001])$.

Regarding time lag, the regression coefficient was significant and negative. This suggests that the magnitude of the "school discipline and self-control" association is smaller for studies that assess school discipline and self-control in a longer time interval.

\section{[INSERT TABLE 4 ABOUT HERE]}

\section{Multiple moderator model}

There could be multicollinearity issues among moderators because they can be interrelated, thus inflating the moderation effect of individual moderator (Hox et al., 2010). To deal with these problems and explore which moderators have unique moderating effect on the overall effect size, we conducted a multiple-moderator model. In this model, we included all the significant moderators found above into a single regression model. The results are summarized in Table 5. Results of the Omnibus test found that the model was significant, $F(10,215)=3.274, p<.001$, which suggested that at least one coefficient of the moderators significantly differed from zero. The results showed that teacher-student relationship (vs. structure) and consistence of report informant of self-control measure had unique moderating effects on the association between school discipline and self-control.

[INSERT TABLE 5 ABOUT HERE]

\section{Publication bias}


According to Ferguson and Brannick (2012), including grey literature is as likely to yield publication bias as excluding them. Thus, we assumed little influence of publication bias on our findings. To statistically examine this assumption, we scrutinized the effect sizes in the funnel plot (Figure 2) and applied Egger's regression test (Egger et al., 1997; Torgerson, 2006) to examine the significance of the asymmetry of the funnel plot. The results did not reveal significant asymmetry of the funnel plot $(z=-0.812, p=.417)$, suggesting that there was no significant publication bias for the results found above.

\section{Recommendation of sample size for future research}

We foresee that the relationship between school discipline and self-control will continue to attract scientific attention in the future. Thus, we used $\mathrm{G}^{*}$ Power (Faul et al., 2007) to calculate the sample sizes needed to achieve the average correlations found in this study. The results are summarized in Table 6. Specifically, we set alpha level at .05 and included four types of statistical power (i.e., .80, .90, .95, and .99). For instance, to detect a correlation of .189 (the overall association between school discipline and self-control) at alpha of .05 , about $217,290,358$, and 505 participants are needed to achieve $.80, .90, .95$, and .99 power, respectively. Likewise, to detect a correlation of .121 (the overall association between structure and self-control) at alpha of .05 , about $533,713,881$, and 1245 participants are needed to achieve $.80, .90, .95$, and .99 power, respectively.

\section{[INSERT TABLE 6 ABOUT HERE]}

\section{Discussion}

School is a crucial context for human development (Bronfenbrenner, 1979; Downer et al., 2010). School discipline has been theorized as a critical factor that instills students 
with self-control (Gottfredson \& Hirschi, 1990; Sameroff, 2010). This three-level meta-analysis is the first to synthesize the association between three components of school discipline (i.e., structure, support, and teacher-student relationship) and self-control from preschool to middle school. Our findings showed that: (a) school discipline is positively related to self-control, and (b) the overall effect size is largely invariant across school levels, discipline level, culture, report informant of school discipline or self-control, research design, students' sex, age, and ethnicity, but (3) that the overall effect size is moderated by types of school discipline and report informant consistency. These results offer a rich description of whether and how school discipline is associated with self-control in students.

The overall effect size is uniquely moderated by a few factors, including component of school discipline and consistency of report informant. For component of school discipline, we found that the magnitude of the association between teacher-student relationship and self-control was stronger than the ones between structure / support and self-control, while the effect sizes for structure were not significantly different from the ones for support. This is consistent with the theoretical claim that a high-quality relationship between teachers and students is the foundation in teaching students' self-control (Gottrfredson \& Hirschi, 1990). For consistency of report informant, effect sizes for studies using the same approaches to assess school discipline and self-control are stronger than for the ones using different informants. This result concurs with prior studies (Meyer et al., 2001; Willems et al., 2018).

Previous meta-analyses have synthesized the overall relationships between a number of factors and self-control, including genes and family-related variables (Davis et 
al., 2017; Karreman et al., 2006; Li et al., 2019; Pallini et al., 2018; Willems et al., 2018, 2019). Davis et al. (2017) found that parent-child synchrony during early childhood was related to youth self-regulation $(r=.32)$. Karreman et al. (2006) found that parents' positive $(r=.08)$ and negative control $(r=.11)$ were related to preschoolers' self-regulation. Li et al. (2019) revealed that parenting was positively related to self-control in adolescents aged 10-22 both concurrently $(r=.20)$ and longitudinally $(r=.16)$. Pallini et al. (2018) found that the relationship between attachment styles and self-control among children up to 18 years old differed across styles $(r=.10$ to .20$)$. In addition, family violence $(r=-.19$; Willems et al., 2018, with adolescents as samples) and genetic variations (heritability of self-control about 60\%; Willems et al., 2019) are also related to self-control. Compared to previous findings, our results indicate that the strength of school discipline and self-control in children and adolescents (overall $r=.189$ ) is similar to the ones found by Li et al. (2019) and Willems et al. (2018), lower than the ones by Davis et al. (2017), and higher than the ones by Karreman et al. (2006). Consistent with the bioecological model (Bronfenbrenner \& Ceci, 1994), these effect sizes suggest the importance of both genetic and environmental (e.g., family and school) factors in the individual differences in self-control.

\section{Theoretical and practical implications}

The current findings advance our theoretical understandings and practical exercises in several aspects. First, the importance of self-control to child and adolescent development has triggered scholars' attention to investigate the etiological sources of self-control. The bioecological model underlines that both biological and environmental factors co-shape developmental outcomes (Bronfenbrenner \& Morris, 2006). The current meta-analysis 
contributes to the literature which mainly focuses on the family context (Davis et al., 2017; Karreman et al., 2006; Li et al., 2019; Pallini et al., 2018; Willems et al., 2018), by providing a nuanced synthesis of the association between school discipline and self-control. These results largely support the tenets from the general theory of crime (Gottfredson \& Hirschi, 1990) and the transactional model of self-regulation (Sameroff, 2010). They also support attachment theory (Bowlby, 1969) showing that teachers and school can be considered as critical attachment figures and contexts for students and play an important role in students' self-control.

Second, school discipline has been linked to a wide range of positive outcomes in students, such as higher school engagement, better academic achievement, less bullying, and so on (e.g., Gregory et al., 2010; Roorda et al., 2011; Vandenbroucke et al., 2018). With the findings of this study, one may possibly propose that self-control could be a candidate that links school discipline and different outcomes, implying that self-control may be a mechanism explaining how school discipline works in relating to a number of positive outcomes.

Third, in educational psychology, there is a wide debate about which practice should be used to discipline students, ranging from strict conformity to autonomy-granting and independent decision-making (e.g., Kupchik, 2010; Stronach \& Piper, 2008). In the last two decades, psychologists and educationalists have suggested that each approach (e.g., structure, support, teacher-student relationship) is important and recommended taking them into account for practice (e.g., Gregory \& Cornell, 2009; Gregory et al., 2010; Jia et al., 2016; Konold et al., 2014). Consistent with these notions, in this study we found that each 
of the three discipline components is positively related to self-control. However, we also found that the strength differs, with the correlation for teacher-student relationship $(r=.231)$ being significantly larger than the ones for structure $(r=.121)$ and support $(r=.164)$. This implies that although all three components provide leverage points for intervention and/or prevention efforts, a high-quality teacher-student relationship is particularly important in shaping students' self-control.

Fourth, initially we considered that the association between school discipline and self-control could be stronger in middle school. However, this assumption was only supported by the individual test of moderators but not supported by the results of the multiple-moderator test. This suggests that the moderating effect of school level may be overshadowed by other relevant factors (e.g., age). Nevertheless, the significance of school levels in the individual moderator test, may concur with the developmental characteristics of adolescence ------ adolescents may need more aid from external discipline (e.g., school discipline) to maintain and strengthen their self-control, because their self-control falters in this unique developmental stage (Casey \& Caudle, 2013). Taken together, the current findings, although not conclusive, imply that while the relationship between school discipline and self-control shows similar strength from preschool to middle school, school discipline seems to play a more significant role in middle school students' self-control.

Fifth, in educational psychology, scholars consider that students and teachers have different perceptions about school discipline and thus often assess this construct from both perspectives (e.g., Cadima, Doumen, Verschueren, \& Buyse, 2015; de Wilde, Koot, \& van Lier, 2016). Our findings showed that both students' and teachers' perception of school 
discipline are related to students' self-control ability. This suggests that either perspective seems equally useful in studying the relationship between school discipline and self-control.

Last, prior studies have considered discipline at the school and at the classroom levels and found that discipline at both levels are important to students' outcomes (e.g., Gregory et al., 2010; Gregory \& Weinstein, 2008). Concurring with the literature, our results suggest that school-wide discipline and classroom-wide discipline show similar associations with students' self-control. This implies that neither school-wide nor classroom-wide discipline is sufficient in explaining self-control, and that educators may need to maintain discipline at different levels to better nurture students' self-control.

\section{Limitations}

The findings should be interpreted with caution. First, the number of effect size was disproportionally distributed in some subcategories. For instance, for "component of school discipline", the teacher-student relationship component had nearly 1.5 and 2.5 times more effect sizes than the support and structure components, respectively, which may make the associations for each component less comparable.

Second, although we considered a wide range of moderators, other moderators may be relevant to the "school discipline - self-control" association (e.g., family SES, teachers' teaching experience, etc.). However, the available data prevented us from doing so. For instance, interesting but not tested moderators contained too few cases (e.g., student perspective). In addition, some moderators were not in the same unit and thus we could not combine them. For instance, for family SES some studies reported family income while 
others reported parental occupation. This issue, however, could be revisited once more information is obtained in the future. Given that our current coding scheme is open access, extending the analyses in future research should be feasible.

Third, the generalizability of the findings is limited. This meta-analysis only focuses on typically developing students, and thus the findings cannot be readily generalized to clinical samples such as students diagnosed with attention problems or autistic spectrum disorder. Besides, although the effect sizes were drawn from six continents, most of them were from the U.S. and European countries (88.26\%). Future research focusing on the under-represented populations or integrating findings published in different languages into our open-access dataset to update the results would be particularly promising.

Last, in our analyses we quantified concurrent and longitudinal associations, which does not necessarily measure change in self-control since we do not control for baseline levels or autoregressive effects. Conceptually, some studies did control for the baseline levels of self-control, but they also controlled for other covariates and these covariates were not consistent across studies, thus making the findings less comparable. Methodologically, although some new techniques currently allow examining changes in self-control such as metaSEM (Cheung, 2015), these techniques are not compatible with the three-level technique used in this study. Nevertheless, this issue could be reexamined in the future as statistical approach becomes more sophisticated and available.

\section{Future directions}

First, a number of measurements have been developed to assess self-control, 
including self-report and other-report questionnaires, self-control tasks such as Stroop task (for a review, see Duckworth \& Kern, 2010). In this study, only few studies used more than one measure to assess self-control (i.e., composite), while the overwhelming majority used only one assessment modality (i.e., self-report, other-report, observation/task). Since self-control is a multifaceted construct, it has been argued that using more than one approach to assess self-control may better represent the breadth of this construct (Duckworth \& Kern, 2011; Li \& Vazsonyi, 2019). Future research may use multiple modalities to assess self-control and examine their associations with school discipline.

Second, the current study, as well as a prior meta-analysis (Vandenbroucke et al., 2018), only examined the main effect of different components of school discipline on self-control. However, it is considered that these different components complement each other and interact in facilitating students' development (e.g., Gottfredson \& Hirschi, 1990; Gregory et al., 2010). In this sense, it would be interesting to investigate whether different components of school discipline jointly affect self-control in students.

Third, although school-level and classroom-level are both important in associating with self-control, scant research has examined their interaction. It would be promising to examine whether classroom-level and school-level discipline reinforce each other and examine their interaction. For example, it would be interesting to investigate whether the classroom-level can make up for a lack of discipline at the school-level.

Fourth, it is theorized that self-control is co-shaped by biological underpinnings and multiple environmental contexts (e.g., Sameroff, 2010). Some existing studies have examined how biological factors interact with environmental contexts to affect self-control, 
but these studies almost exclusively highlight the family context (e.g., Beaver, Ferguson, \& Lynn-Whaley, 2010; Willems et al., 2019), largely ignoring the interaction between biological factors and the school context. In addition, although some studies have examined the interaction between home and school in forging students' self-control (e.g., Li \& Lau, 2019; Turner et al., 2015), this line of research is still in its infancy. The investigation of the interaction between other ecological systems and school discipline and the one between biological factors and school context on students' self-control could be promising avenues of research.

Last, the transactional model of self-regulation (Sameroff, 2010) suggests that contextual factors affect self-control and vice versa. Evidence on the relationship between parenting and self-control reveals that parenting predicts adolescents' later self-control, and that adolescents' self-control also predicts later parenting (Li et al., 2019). In future studies, modeling whether school discipline and self-control show a bidirectional association could be another interesting topic. For example, when teachers know students are good at self-control, teachers may grant more autonomy and support and use less harsh discipline. Moreover, students with high self-control may have better academic achievement and relationships with others (e.g., Duckworth \& Seligman, 2005; Tangney et al., 2004), which could be beneficial for a good teacher-student relationship. In sum, it would be promising for future research to examine such a bidirectional association.

\section{Conclusion}

Self-control aids children and adolescents to navigate the challenges during the developmental process to achieve optimal outcomes (Caspi et al., 2016; Moffitt et al., 2011, 
2013). The current meta-analysis suggests that school discipline is significantly associated with self-control spanning the developmental period from preschool to middle school. This association was not affected by students' age, sex, and ethnicity, school levels, discipline level, cultural factors (i.e., individualism and power distance), report informant of school discipline or self-control measures, or research design. The association is stronger for the teacher-student relationship component and for effect sizes obtained from consistent report informants. Together, these findings highlight that school discipline, particularly a qualitative teacher-students relationship, is important to the individual differences in self-control among preschoolers to middle school students. 


\section{References}

This part is deliberately omitted until the paper is accepted. 
Table 1 Counts of effect sizes

\begin{tabular}{|c|c|c|}
\hline & $\mathrm{N}$ & $\%$ \\
\hline \multicolumn{3}{|l|}{ Dimension of school discipline } \\
\hline Structure & 44 & $17.8 \%$ \\
\hline Support & 85 & $34.4 \%$ \\
\hline Teacher-student relationship & 118 & $47.8 \%$ \\
\hline \multicolumn{3}{|l|}{ School level } \\
\hline Within preschool & 111 & $44.9 \%$ \\
\hline Within primary school & 39 & $15.8 \%$ \\
\hline Within middle school & 79 & $32.0 \%$ \\
\hline Between school periods (transition between periods) & 10 & $4.0 \%$ \\
\hline Mix periods (samples consist of more than one period) & 8 & $3.2 \%$ \\
\hline \multicolumn{3}{|l|}{ Ethnicity of students } \\
\hline Balanced, no dominant ethnicity & 77 & $31.1 \%$ \\
\hline Most white (Euro-American) $(>60 \%)$ & 132 & $53.4 \%$ \\
\hline Most African or African American (> 60\%) & 14 & $5.7 \%$ \\
\hline Most Asian or Asian American (> 60\%) & 11 & $4.5 \%$ \\
\hline Most Hispanic $(>60 \%)$ & 7 & $2.8 \%$ \\
\hline Missing data & 6 & $2.4 \%$ \\
\hline \multicolumn{3}{|l|}{ Discipline level } \\
\hline School wide & 60 & $24.3 \%$ \\
\hline Classroom wide & 187 & $75.7 \%$ \\
\hline \multicolumn{3}{|l|}{ Report informant of school discipline measure } \\
\hline Self-report & 92 & $37.2 \%$ \\
\hline Other-report (teacher-report only) & 71 & $28.7 \%$ \\
\hline Observation/task & 71 & $28.7 \%$ \\
\hline Composite & 10 & $4.0 \%$ \\
\hline Missing data & $3^{\mathrm{a}}$ & $1.2 \%$ \\
\hline \multicolumn{3}{|l|}{ Report informant of self-control measure } \\
\hline Self-report & 88 & $35.6 \%$ \\
\hline Other-report (teacher-report and parent-report) & 58 & $23.5 \%$ \\
\hline Observation/task & 73 & $29.6 \%$ \\
\hline Composite & 28 & $11.3 \%$ \\
\hline \multicolumn{3}{|l|}{ Consistency of report informant } \\
\hline Consistency & 100 & $40.5 \%$ \\
\hline Inconsistency & 144 & $58.3 \%$ \\
\hline Missing data & 3 & $1.2 \%$ \\
\hline
\end{tabular}


Study design

Cross-sectional study

Longitudinal study

Sex of students (based on boy ratio)

Age of students

Individualism

Power distance

Time lag

Total
$164 \quad 66.4 \%$

$83 \quad 33.6 \%$

$22591.1 \%$

$247 \quad 100 \%$

$241 \quad 97.6 \%$

$241 \quad 97.6 \%$

$247 \quad 100 \%$

$247 \quad 100 \%$

Note: a: in one study, other-report refers to mother-report while the remaining effect sizes all refer to teacher-report, and thus we left this mother-report effect size out from the "other report" category to reflect teachers' perspective of school discipline. In another study, school discipline was measured by reviewing the school record to determine whether the school was punitive school or not. Since this does not match any category and only consists of two cases, we left them out. Hence, we had 3 missing data for this category. Some subcategories are not added up to $100 \%$ due to the rounding of decimals. 
Table 2 Terms of each school discipline factor

\begin{tabular}{|c|c|c|c|}
\hline School discipline Terms & $\begin{array}{l}\text { Structure } \\
(N=44)\end{array}$ & $\begin{array}{l}\text { Support } \\
(N=85)\end{array}$ & $\begin{array}{c}\text { Teacher-student } \\
\text { relationship }(N= \\
118)\end{array}$ \\
\hline Classroom organization & 16 & & \\
\hline School discipline & 5 & & \\
\hline School supervision/control & 4 & & \\
\hline Teachers' instruction of rules & 4 & & \\
\hline School crime \& delinquency & 3 & & \\
\hline $\begin{array}{l}\text { Students' belief in legitimacy of } \\
\text { school rules }\end{array}$ & 3 & & \\
\hline Classroom rule clarity & 3 & & \\
\hline Socialization & 3 & & \\
\hline Classroom chaos & 2 & & \\
\hline School chaos & 1 & & \\
\hline Teacher support & & 20 & \\
\hline Emotional support & & 17 & \\
\hline Autonomy support & & 16 & \\
\hline Instructional support & & 10 & \\
\hline School support & & 7 & \\
\hline Classroom interactions $^{1}$ & & 7 & \\
\hline Organizational support & & 5 & \\
\hline Teachers' labeling & & 1 & \\
\hline School responsiveness & & 1 & \\
\hline Teachers' child-centered belief & & 1 & \\
\hline Teacher-student closeness & & & 40 \\
\hline Teacher-student conflict & & & 24 \\
\hline Attachment to school & & & 24 \\
\hline School connectedness & & & 8 \\
\hline Teachers' sensitivity & & & 8 \\
\hline Attachment to teacher & & & 5 \\
\hline School avoidance & & & 4 \\
\hline Students' dependency on teacher & & & 3 \\
\hline $\begin{array}{ll}\text { General teacher-student } \\
\text { relationship }\end{array}$ & & & 2 \\
\hline
\end{tabular}

Note: 1: Interaction in this case refers to the composite of emotional and instructional support (the support dimension) and organization (the structure dimension). Since this composite comprises two dimensions for support, we gave more weights to the support dimension and thus approximately coded it as support. 
Table 3 The $Q_{E}$ statistics testing residual heterogeneity and the Omnibus to test the effect of the moderators

\begin{tabular}{lcccc}
\hline \multicolumn{1}{c}{ Moderator } & $Q_{E}(d f)$ & $p$ & Omnibus test & $p$ \\
\hline Dimension of school discipline & $3305.091(244)$ & $<.001$ & $F(2,244)=5.524$ & .005 \\
Sex of students & $4064.804(223)$ & $<.001$ & $F(1,223)=0.663$ & .416 \\
Age of students & $4124.764(245)$ & $<.001$ & $F(1,245)=8.117$ & .005 \\
School level & $3743.528(226)$ & $<.001$ & $F(2,226)=4.123$ & .017 \\
Individualism & $5155.430(242)$ & $<.001$ & $F(1,242)=.001$ & .969 \\
Power distance & $4407.182(239)$ & $<.001$ & $F(1,239)=1.372$ & .243 \\
Ethnicity of students & $3882.399(236)$ & $<.001$ & $F(4,236)=1.467$ & .213 \\
Discipline level & $4025.729(245)$ & $<.001$ & $F(1,245)=0.286$ & .593 \\
Report informant of school discipline measure & $3254.205(240)$ & $<.001$ & $F(3,240)=2.146$ & .095 \\
Report informant of self-control measure & $3815.920(243)$ & $<.001$ & $F(3,243)=7.015$ & $<.001$ \\
Consistency of report informant & $4005.349(242)$ & $<.001$ & $F(1,242)=23.512$ & $<.001$ \\
Research design & $4394.913(245)$ & $<.001$ & $F(1,245)=4.098$ & .044 \\
Time lag & $4485.387(245)$ & $<.001$ & $F(1,245)=5.083$ & .025 \\
\hline
\end{tabular}


Table 4 Summary of results for significant moderators

\begin{tabular}{|c|c|c|c|c|c|c|c|c|}
\hline Moderator & $\# E S$ & $E S_{z}$ & $S E$ & $t$ & $95 \% \mathrm{CI}\left(E S_{z}\right)$ & $p$ & $r$ & $95 \% \mathrm{CI}(r)$ \\
\hline Dimension of school discipline & 247 & & & & & & & \\
\hline Structure & 44 & 0.122 & 0.030 & 3.993 & {$[0.062,0.182]$} & $<.001$ & .121 & {$[.062, .180]$} \\
\hline Support & 85 & 0.165 & 0.028 & 5.947 & {$[0.110,0.219]$} & $<.001$ & .164 & {$[.110, .216]$} \\
\hline Teacher-student relationship & 118 & 0.235 & 0.024 & 9.688 & {$[0.188,0.283]$} & $<.001$ & .231 & {$[.186, .276]$} \\
\hline$\Delta$ slope of structure (vs. support) & & 0.043 & 0.032 & 1.348 & {$[-0.020,0.105]$} & .179 & & \\
\hline$\Delta$ slope of structure (vs. teacher-student relationship) & & 0.114 & 0.035 & 3.277 & {$[0.045,0.182]$} & .001 & & \\
\hline$\Delta$ slope of support (vs. teacher-student relationship) & & 0.071 & 0.032 & 2.247 & {$[0.009,0.133]$} & .026 & & \\
\hline \multicolumn{9}{|l|}{ School period } \\
\hline Within kindergarten & 111 & 0.160 & 0.032 & 4.999 & {$[0.097,0.223]$} & $<.001$ & .159 & {$[.097, .219]$} \\
\hline Within primary school & 39 & 0.138 & 0.042 & 3.290 & {$[0.055,0.221]$} & .001 & .137 & {$[.055, .217]$} \\
\hline Within middle school & 79 & 0.281 & 0.036 & 7.741 & {$[0.209,0.353]$} & $<.001$ & .274 & {$[.206, .339]$} \\
\hline$\Delta$ slope of within kindergarten (vs. within primary school) & & -0.022 & 0.049 & -0.445 & {$[-0.118,0.075]$} & .657 & & \\
\hline$\Delta$ slope of within kindergarten (vs. within middle school) & & 0.121 & 0.048 & 2.501 & {$[0.026,0.216]$} & .013 & & \\
\hline$\Delta$ slope of within primary school (vs. within middle school) & & 0.143 & 0.056 & 2.573 & {$[0.033,0.252]$} & .011 & & \\
\hline Age of students & 247 & 0.013 & 0.005 & 2.849 & {$[0.004,0.022]$} & .005 & - & - \\
\hline Report informant of self-control measure & 247 & & & & & & & \\
\hline Self-report & 88 & 0.283 & 0.030 & 9.518 & {$[0.225,0.342]$} & $<.001$ & .276 & {$[.221, .329]$} \\
\hline Other-report & 58 & 0.194 & 0.031 & 6.324 & {$[0.134,0.254]$} & $<.001$ & .192 & {$[.133, .249]$} \\
\hline Observation/task & 73 & 0.107 & 0.030 & 3.617 & {$[0.049,0.166]$} & $<.001$ & .107 & {$[.049, .164]$} \\
\hline Composite & 28 & 0.094 & 0.049 & 1.927 & {$[-0.002,0.191]$} & .055 & .094 & {$[-.002, .189]$} \\
\hline$\Delta$ slope of self-report (vs. other-report) & & -0.089 & 0.038 & -2.357 & {$[-0.164,-0.015]$} & .019 & & \\
\hline$\Delta$ slope of self-report (vs. observation/task) & & -0.176 & 0.040 & -4.364 & {$[-0.255,-0.097]$} & $<.001$ & & \\
\hline$\Delta$ slope of self-report (vs. composite) & & -0.189 & 0.057 & -3.322 & {$[-0.301,-0.077]$} & .001 & & \\
\hline
\end{tabular}




\begin{tabular}{|c|c|c|c|c|c|c|c|c|}
\hline$\Delta$ slope of other-report (vs. observation/task) & & -0.087 & 0.034 & -2.539 & {$[-0.154,-0.019]$} & .012 & & \\
\hline$\Delta$ slope of other-report (vs. composite) & & -0.100 & 0.055 & -1.797 & {$[-0.209,0.010]$} & .074 & & \\
\hline$\Delta$ slope of observation/task (vs. composite) & & -0.013 & 0.051 & -0.253 & {$[-0.112,0.087]$} & .801 & & \\
\hline Consistency of report informant & 244 & & & & & & & \\
\hline Consistent informant & 100 & 0.275 & 0.026 & 10.424 & {$[0.223,0.327]$} & $<.001$ & .268 & {$[.219, .316]$} \\
\hline Inconsistent informant & 144 & 0.133 & 0.024 & 5.566 & {$[0.086,0.181]$} & $<.001$ & .132 & {$[.086, .179]$} \\
\hline$\Delta$ slope of consistent (vs. inconsistent) & & -0.141 & 0.029 & -4.849 & {$[-0.199,-0.084]$} & $<.001$ & & \\
\hline Research design & 247 & & & & & & & \\
\hline Cross-sectional design & 164 & 0.204 & 0.022 & 9.350 & {$[0.161,0.246]$} & $<.001$ & .201 & {$[.160, .241]$} \\
\hline Longitudinal design & 83 & 0.156 & 0.027 & 5.713 & {$[0.102,0.209]$} & $<.001$ & .155 & {$[.102, .206]$} \\
\hline$\Delta$ slope of cross-sectional (vs. longitudinal) & & -0.048 & 0.024 & -2.024 & {$[-0.094,-0.001]$} & .044 & & \\
\hline Time lag & 247 & -0.035 & 0.015 & -2.255 & {$[-0.065,-0.004]$} & .025 & - & - \\
\hline
\end{tabular}

Note: Pearson correlation $r$ and its $95 \%$ confidence interval were transformed back from the $E S_{z}$ and its $95 \%$ confidence interval respectively using the inverse version of the Fisher's $r$-to- $z$ formula. $E S=$ effect size. 
Table 5 Summary of results for the multiple moderator model

\begin{tabular}{|c|c|c|c|c|}
\hline Moderator & $\beta(\mathrm{SE})$ & $95 \% \mathrm{CI}$ & $t$ & $p$ \\
\hline Intercept & $0.236(0.091)$ & {$[0.056,0.415]$} & 2.592 & .010 \\
\hline Dimension of school discipline: support (vs. structure) & $0.039(0.032)$ & {$[-0.024,0.102]$} & 1.220 & .224 \\
\hline Dimension of school discipline: teacher-student relationship (vs. structure) & $0.089(0.037)$ & {$[0.017,0.161]$} & 2.438 & .016 \\
\hline Age of students & $-0.033(0.013)$ & {$[-0.029,0.022]$} & -0.267 & .790 \\
\hline School level: within primary school (vs. within kindergarten) & $-0.014(0.061)$ & {$[-0.134,0.107]$} & -0.221 & .825 \\
\hline School level: within middle school (vs. within kindergarten) & $0.036(0.130)$ & {$[-0.220,0.293]$} & 0.279 & .780 \\
\hline Report informant of self-control measure: other-report (vs. self-report) & $0.036(0.043)$ & {$[-0.047,0.120]$} & 0.856 & .393 \\
\hline Report informant of self-control measure: observation/task (vs. self-report) & $-0.018(0.045)$ & {$[-0.106,0.070]$} & -0.408 & .684 \\
\hline Consistency of report informant: inconsistent (vs. consistent) & $-0.125(0.039)$ & {$[-0.203,-0.047]$} & -3.159 & .002 \\
\hline Research design: cross-sectional (vs. longitudinal) & $0.009(0.036)$ & {$[-0.061,0.080]$} & 0.263 & .793 \\
\hline Time lag & $-0.041(0.027)$ & {$[-0.095,0.012]$} & -1.522 & .130 \\
\hline Omnibus test & \multicolumn{4}{|c|}{$F(10,215)=3.274, p<.001$} \\
\hline Variance within study & \multicolumn{4}{|l|}{$.009, p<.001$} \\
\hline Variance between study & \multicolumn{4}{|l|}{$.021, p<.001$} \\
\hline Number of effect sizes & \multicolumn{4}{|l|}{226} \\
\hline
\end{tabular}

Note: $\mathrm{CI}=$ confidence interval. 
Table 6 Recommendation of sample sizes

\begin{tabular}{lcccc}
\hline \multirow{2}{*}{ Correlations } & \multicolumn{4}{c}{ Power } \\
\cline { 2 - 5 } & .80 & .90 & .95 & .99 \\
\hline Overall $(r=.189)$ & 217 & 290 & 358 & 505 \\
Structural $(r=.121)$ & 533 & 713 & 881 & 1245 \\
Support $(r=.164)$ & 289 & 386 & 477 & 674 \\
Teacher-student relationship $(r=.231)$ & 144 & 192 & 237 & 335 \\
\hline
\end{tabular}

Note:

G*Power version: 3.1.9.2.

Cronbach's alpha was set at 05 .

Tails: two.

Test family: exact.

Statistical Test: correlation bivariate normal model. 


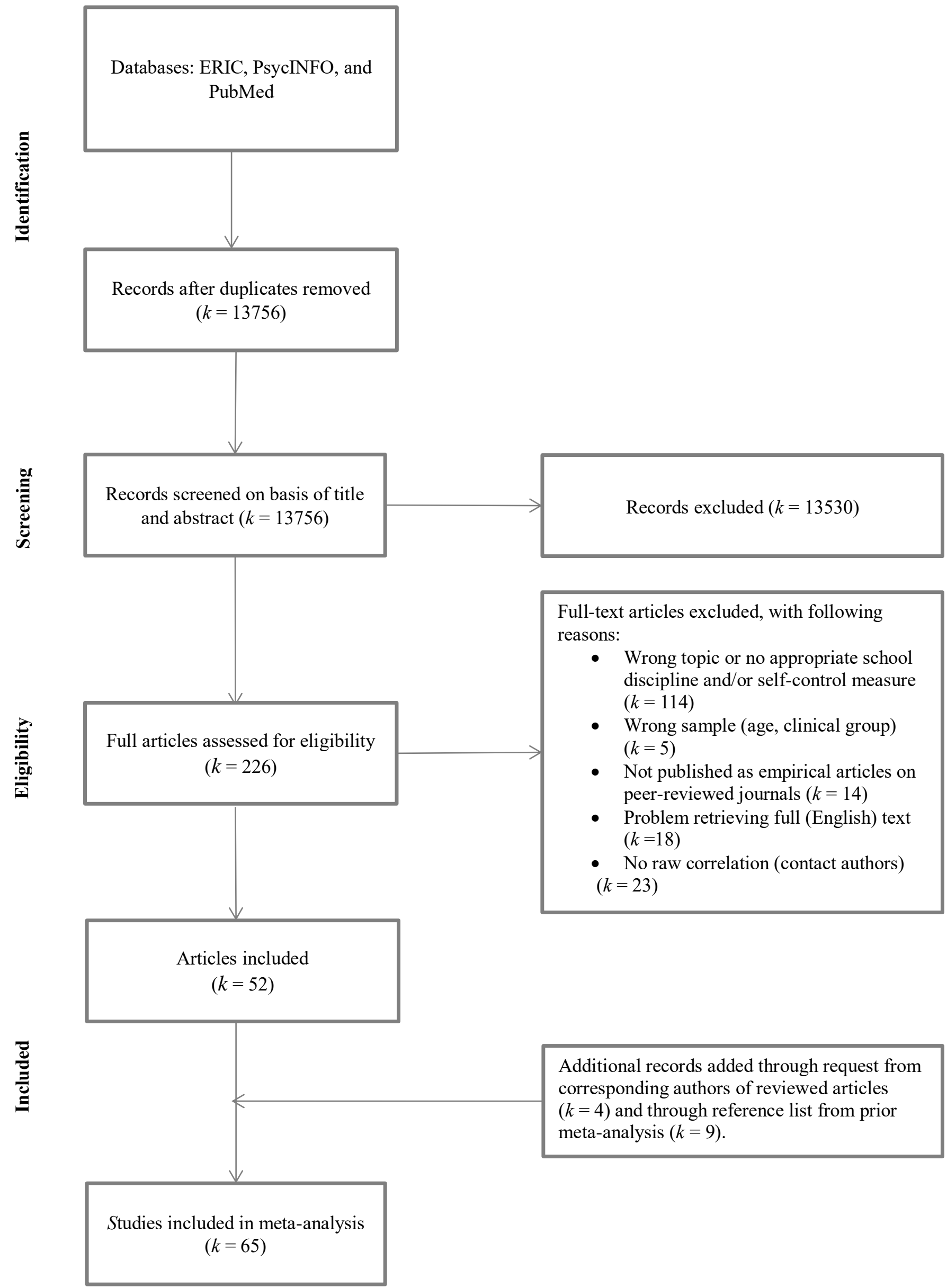

Figure 1 PRISMA flowchart used to identify studies for detailed analysis of school discipline and self-control 


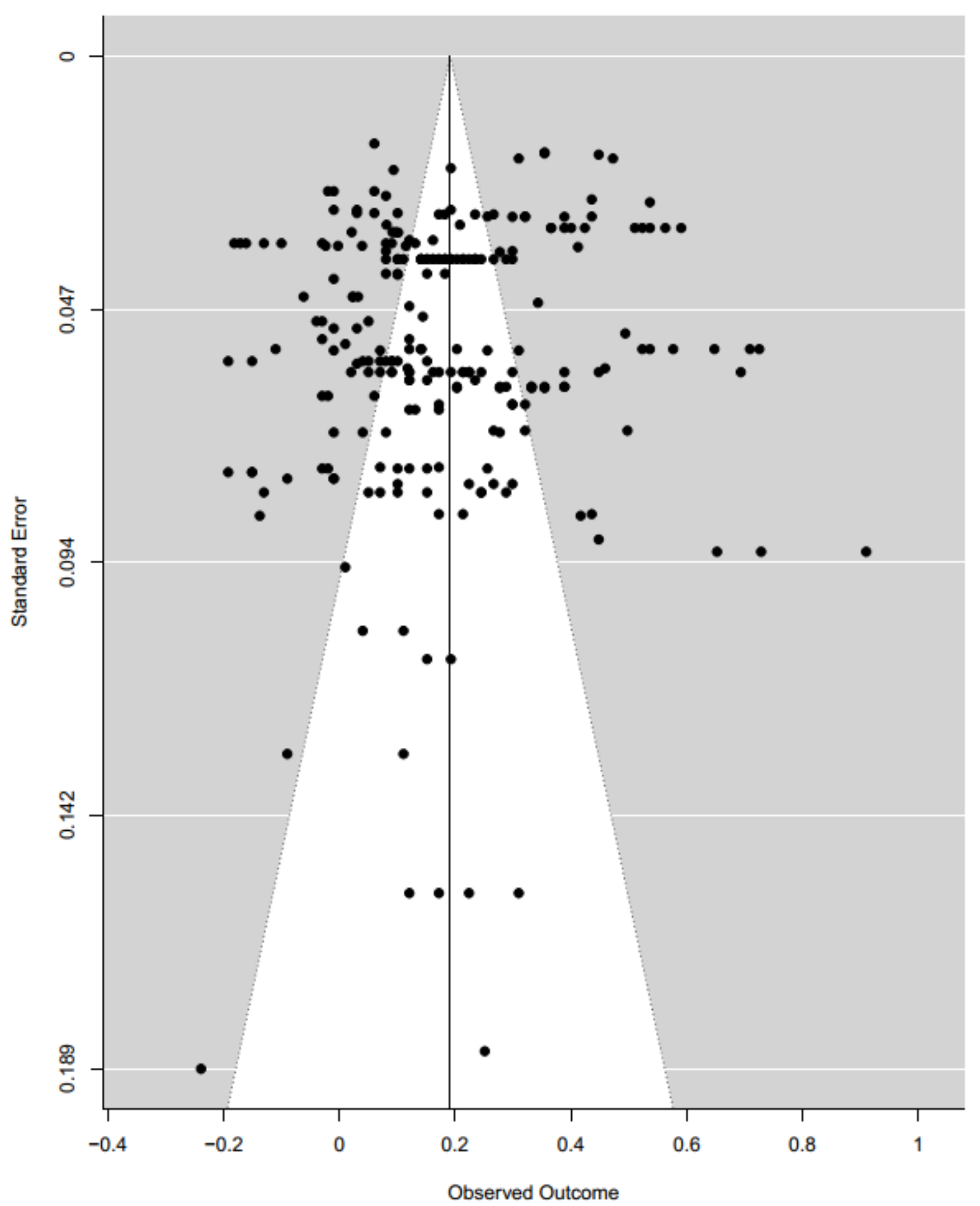

Figure 2 Funnel plot for the associations between school discipline and self-control 